\title{
Dynamical In Situ Study of Morphological Changes of Bentonite in ESEM
}

\author{
Eva Navrátilová ${ }^{1}$, Vilém Neděla ${ }^{1}$, Haiquan Sun $^{2}$ and David Mašín ${ }^{2}$ \\ 1. Environmental Electron Microscopy Group, Institute of Scientific Instruments of the CAS, Brno, \\ Czech Republic \\ 2. Institute of Hydrogeology, Engineering Geology and Applied Geophysics, Charles University, Prague, \\ Czech Republic
}

The bentonite has a variety of industrial applications. It is used as a stabilizing and suspending agent, an adsorbent and clarifying agent, a buffer material for barriers in geological disposal facilities for radioactive waste, liners for remediation of contaminated soils and ponds. Characterization of the morphological changes of the bentonite during the process of swelling and shrinkage is very important for these applications [1-3]. The environmental scanning electron microscope (ESEM) allows observation under the water vapour pressure from units to thousands of $\mathrm{Pa}$ and at a selected temperature from $-20^{\circ} \mathrm{C}$ to $1500^{\circ} \mathrm{C}$. Moreover, these samples do not have to be treated, namely dried and covered with the conductive metal layer $[1,4]$. ESEM is also very effective for in-situ investigation of bentonites, which can be realised under dynamically changing relative humidity (RH).

Dynamical is-situ observation of morphological changes in shape and size of the bentonite under varying RH was performed in the HR ESEM QUANTA 650 FEG. The bentonite was placed on a conical Peltier-cooled holder and observed under constant stage temperature of $5{ }^{\circ} \mathrm{C}$. The experiment starts under the water vapour pressure of $93 \mathrm{~Pa}$ and the $\mathrm{RH}$ of $10 \%$ using specimens which have previously been equilibrated at total suction of $286.7 \mathrm{MPa}(\mathrm{RH}$ of $12 \%)$. The gas pressure was then gradually increased up to the RH of $97 \%$ with the corresponding gas pressure of $850 \mathrm{~Pa}$. After reaching the maximum value of the $\mathrm{RH}$ at which the sample was still observable, the relative humidity was gradually decreased in several steps. At each step a certain RH was stabilized and the sample was kept under those conditions for 15 minutes. The swelling of the bentonite was measured on a selected spherical particle (the circled areas in the figure 1B) in the vertical and horizontal direction using the software Scandium. Other observation parameters were kept constant throughout the experiment; the beam energy of $20 \mathrm{keV}$, the beam current of $124 \mathrm{pA}$, the working distance of $8 \mathrm{~mm}$.

Figures $1 \mathrm{AI}$ and $1 \mathrm{AII}$ show the sample before starting the wetting and after drying. The morphological and dimensional changes of the bentonite during wetting and drying can be seen in figures $1 \mathrm{~B}-1 \mathrm{~F}$. The state of the maximum swelling of the sample covered in water (the maximal $\mathrm{RH}$ of $97 \%$ before flooding) can be seen in Fig. 1D. As known from unsaturated soil mechanics of double porosity media, in this state the macropores (pores between the bentonite aggregates) of the sample start to fill up and the aggregate surface is no-more clearly observable. The results of the swelling experiment on the selected bentonite particle are presented in Fig. 2. The enlargement of the spherical particle is approximately isotropic (equal in both the horizontal and vertical directions). It can be seen that the swelling of the particle is very small up to the $\mathrm{RH}$ of $30 \%$, where the micropores in the aggregate fill up with water without substantial effect on aggregate size. From the RH of $30 \%$ to the RH of $80 \%$ the swelling is more pronounced. Rapid swelling then occurs between RH 80\% and RH 97\%. Fig. 2 shows that the average dependency of the relative swelling (in \%) on the RH can be fitted with the formula0.0458 $\mathrm{e}^{0.0616 \cdot x}$. The use of the ESEM is effective for studying morphological changes on the bentonite caused by swelling and shrinking. All requests for poster presentations will be honored [5]. 


\section{References:}

[1] G Montes-H, J. Colloid Interface Sci. 284 (2005), p. 271.

[2] AB Jacinto, A Ledesma and A Demagistri, Geomech. Energy Environ. 8 (2016), p. 52.

[3] E Caballero, C Jiménez de Cisneros, Chem. Erde 71 (2011), p. 389.

[4] G Montes-H, J Duplay and L Martinez, Appl. Clay Sci. 23 (2003), p. 309.

[5] The European Commission (ALISI No. CZ.1.05/2.1.00/01.0017).
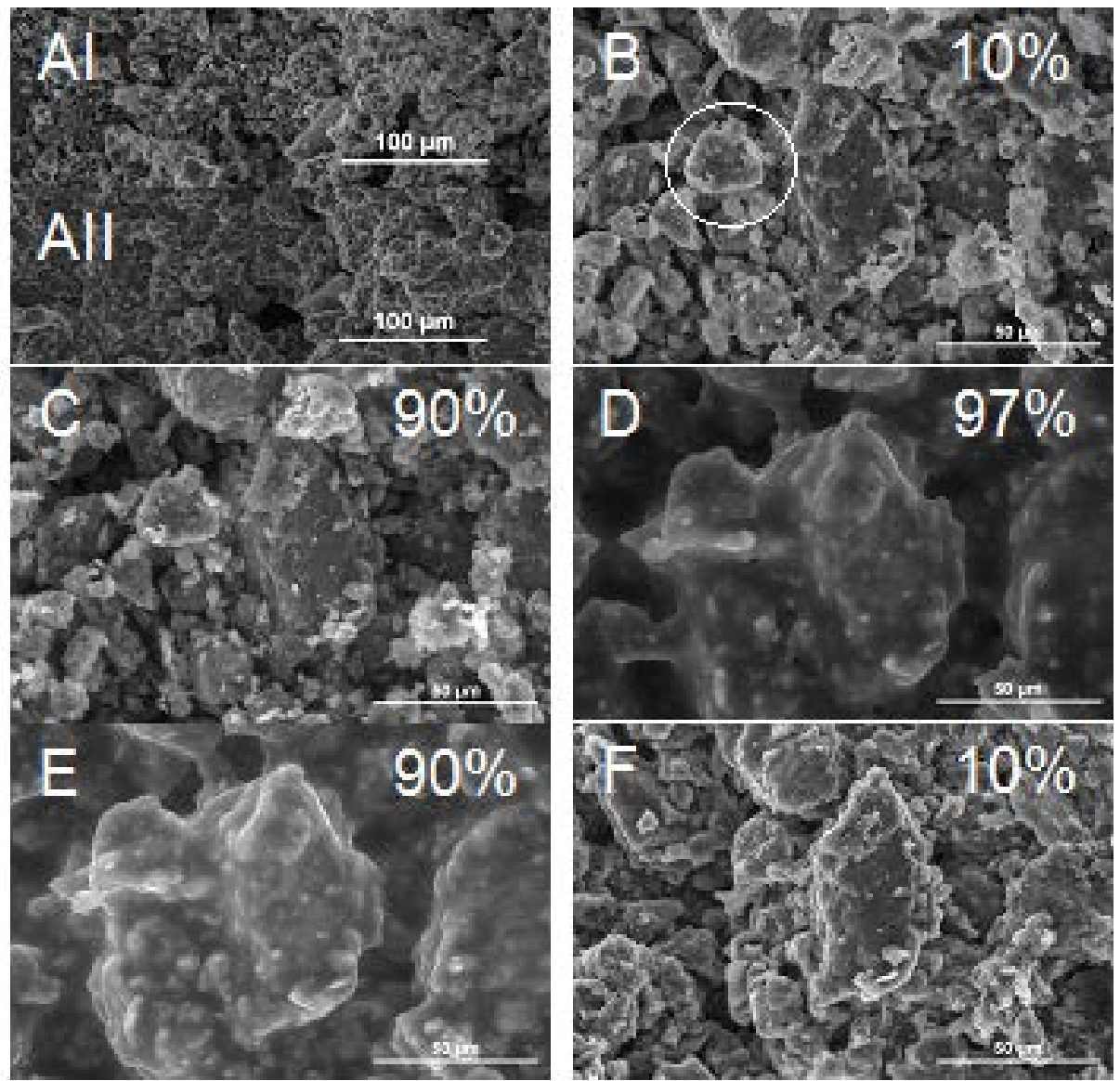

Figure 1. Sample of bentonite before wetting (AI) and after drying (AII). Morphological changes of bentonite during dynamical changing of RH from $10 \%$ to $97 \%$ and down to $10 \%$ (B, C, D, E, F).



Figure 2. Swelling of the bentonite spherical particle, see white circle in figure 1B. 